\title{
ECC
}

Eurasian Chemical Communications

\section{Evaluation of the 1-octanol/water partition coefficient of quinolones and quinolones compounds via free energy estimated in quantum chemical calculations}

\author{
Meysam Shir Mohammadia, Zakiyeh Bayat ${ }^{\mathrm{b}, *}$, Esmat Mohammadinasab $^{\mathrm{a}}$ \\ ${ }^{a}$ Department of Chemistry, Arak Branch, Islamic Azad University, Arak, Iran \\ ${ }^{b}$ Department of Chemistry, Quchan Branch, Islamic Azad University, Quchan, Iran
}

Received: 25 September 2019, Accepted: 16 November 2019, Published: 02 December 2019

\begin{abstract}
A rapid screening assay for the measurement of octanol-water partition coefficients $(\log \mathrm{P})$ of pharmaceuticals such as quinolines, quinolones and fluoroquinolones compounds were developed using quantum chemical calculations. In this paper, we report the $\log \mathrm{P}$ of the pharmaceutical derivative compounds determined by the calculation of the difference in the solvation free energies in water-octanol using the thermodynamic integration method. The $\log \mathrm{P}$ values calculated by this method are closer to the experimental values compared to other ab initio methods. Solvation free energy in water and octanol, free energy of cavity formation in water and Henry's constants, and some other parameters are determined at the density functional theory (DFT) and Hartree-Fock (HF) level with 6-31++G** basis set. Moreover, surface area, mass, refractivity, volume, and polarizability have been calculated for some of the compounds with the same levels.
\end{abstract}

Keywords: Solvation free energy; partition coefficients; ab initio method; quinolone antibiotics; quinoline.

\section{Introduction}

Quinolone and fluoroquinolones derivatives are broad-spectrum antibiotic pharmaceutics. Almost, all quinolone antibiotics in use are fluoroquinolones, which contain a fluorine atom in their chemical structure and are effective against both Gram-negative and Grampositive bacteria [1-5]. Fluoroquinolones are often used for genitourinary infections and are widely used in the treatment of hospital-acquired infections associated with urinary catheters [6,7]. Quinolones exert their antibacterial

*Corresponding author: Zakiyeh Bayat

Tel: +98 (915)1811750, Fax: +98 (51) 47233239

E-mail:z.bayat@ymail.com effect preventing bacterial DNA from unwinding and duplicating. Specifically, they inhibit the ligase activity of the type II topoisomerases, gyrase and topoisomerase IV which cut DNA in order to introduce supercoiling and with their ligase activity disrupted release DNA with single and double strand breaks which lead to cell death $[8,9]$. The majority of quinolones in clinical use are fluoroquinolones, which have a fluorine atom attached to the central ring system, typically, in the 6-position $\left(\mathrm{R}_{6}=\mathrm{F}\right)$

Eurasian Chem. Commun., (2020) 374-386 
(Figure 1). Another batch of compounds studied are quinolines.

Quinoline, 1-azanaphthalene, is an aromatic nitrogen compound characterized by a solid-ring structure containing a benzene fused to pyridine at two adjacent carbon atoms [10]. (Pyridine is a ring structure compound of five carbon atoms with a nitrogen atom) (Figure 2). Quinoline family compounds are widely used as a parent compound to make drugs (especially anti-malarial medicines), fungicides, biocides, alkaloids, dyes, rubber chemicals and flavoring agents. They have antiseptic, antipyretic, and antiperiodic properties [11-13]. They are also used as catalyst, corrosion inhibitor, preservative, and as a solvent for resins and terpenes. They are used in transition-metal complex catalyst chemistry for uniform polymerization and luminescence chemistry. One of the interest project is converting 2-(2-Chloroquinolin-3-yl)-3(arylamino)- 2, 3-dihydroquinazolin-4(1 $\mathrm{H})$-one to quin- olino $\left[2^{\prime}, \quad 3^{\prime}: 3\right.$, 4]pyrazolo[5, 1- b]quinazolin-8(6 $\mathrm{H})-$ ones in the presence of $\mathrm{KO} \mathrm{t} \mathrm{Bu}$ in DMSO at room temperature which is one of the best project .Shiri and his colleagues used a specific method. Their method has the advantages of easy conditions, construction of highly novel five heterocycles, transition metal- free conditions, cascade dehydrogenation and intramolecu- lar $\mathrm{N}$-arylation and good to high yield of products [14]. These are used as an antifoaming agent in refinery field. 1-Octanol/water partition coefficient $(\log \mathrm{P})$, which is the quantitative parameter for an insight into the interaction between drug and biofilm, is one of the most important parameters employed for estimating a chemical's environmental fate and toxicity [15-17]. Partition coefficients are useful in estimating the distribution of drugs within the body [18]. In the pharmaceutical science, partition coefficient is often restricted to water and 1 -octanol [19]. Moreover, $\log P$ is used as an input to evaluate environmental partitioning, absorption, bioavailability, bio-concentration, bio-accumulation, eco-toxicity, human toxicity, pharmacokinetics and pharmacodynamic properties [20]. If $\log \mathrm{P}$ cannot be obtained using the experimental measurement or it is difficult to be determined accurately, calculation or prediction methods must be used [21].

Such methods used for substances which decompose, are soluble, ionizable, and volatile, and have a high surface activity. Furthermore, it is not possible to evaluate the toxicity of all chemicals using experimental methods. Such approaches are difficult to undertake and semi-empirical. Thermodynamic methods are mostly inaccurate, and the statistical mechanical approaches are either inaccurate or will require many molecular and intermolecular parameters, which are generally unavailable. Several methods for the calculation of $\log P$ values have been proposed by different groups of researchers.

In 2003, some investigators have stated that the hydrophobic interaction is of critical importance in many areas of chemistry, including the enzyme-ligand interactions, drug-receptor interactions, transport of drug to the active site, the assembly of lipids in bio-membranes, aggregation of surfactants, coagulation, and detergency [22].

In 2010, Bayat et al. [23] reported that the partition coefficient in nucleoside analogues is the result of a difference in the solubility free energy into water and alcohol octanol.

Jorgensen et al. [24-27] have reported that according to the topological indices, quantum chemistry descriptors, and other indicators, there are many variables 
to measure $\log \mathrm{P}$ values, which have been the response to explore the suitability of the descriptors/schemes in QSAR studies.

In 2008, Kobarfard et al. [28] reported that water distribution ratio of 1-octanol mixture is the ratio of the solubility of the substance in a 1-octanol solution in a water mixture. For a long time, $\log \mathrm{P}$ has been one of the quantitative physical properties that correlate with the biological activity. It is a conventionally used hydrophobic parameter in the studies of quantitative structure-activity relationships and the early stage of an environmental risk assessment course for a chemical. Although it is impossible to theoretically elucidate the partition phenomenon based on the solute/solvent molecular structures, it is also difficult to approach this matter directly, mainly because of the complexity of the phenomenon between two condensed states consisting of a hung number of characteristic particles.

Haeberlein and Brinck have calculated the $\log \mathrm{P}$ using theoretical descriptors derived from the molecular surface area and the electrostatic potential. They used an ab initio SCF approach to compute the molecular descriptors at the HF/6-31G* level. They predicted 1-octanol-water partition coefficient for some molecules with biological activity [29]. Using the ab initio MO-SCRF (self-consistent reaction field) method, Chuman et al. calculated the solvent accessible surface area, the transfer energy from vacuum to solvated sites, and the solvation energy difference of many solute molecules between 1-octanol and water environments. The geometry of the solute molecules was first optimized by the HF calculations with the 3-21G* basis set in the Gaussian 98 package. Then, the results of $\log \mathrm{P}$ values were reported using these two structural quantities by multiple linear-regression analysis. Furthermore, the solvation free energy in water and 1-octanol was calculated with the PCM model by Amovilli et al. [30].

On the other hand, $\log \mathrm{P}$ is related to the interaction between solute and solvent, or solvation free energy. The solvation is a thermodynamic controlled process and can, therefore, be formulated with thermodynamics and statistical mechanics.

\section{Lipophilicity}

The ability of the material to dissolve in lipids and non-polar solvents is called lipophilicity [31]. It is usually represented by the partition coefficients (P) defined as the ratio of the concentrations of a compound in organic and aqueous phases of a twocompartment system under equilibrium conditions.

\section{Partition coefficient}

The logarithm of the partition coefficient is:

$$
\log P=\frac{C_{o c t}}{C_{w}}
$$

Where $\mathrm{C}_{\mathrm{oct}}$ and $\mathrm{C}_{\mathrm{w}}$ are the equilibrium concentrations for a given solute in 1octanol and water, respectively. Partition coefficients should be measured at low concentrations or extrapolated to define dilution of the solute. They are dimensionless measures of the relative affinity of a molecule with respect to the two phases and depend on absorption, transport, and partitioning phenomena. Compounds for which $\mathrm{P}>1$ or $\log \mathrm{P}>0$ are lipophilic, and compounds for which $\mathrm{P}<1$ or $\log \mathrm{P}<0$ are hydrophilic. In particular, lipophilicity depends on the solute bulk, polar and hydrogen-bonding effects. The most widely used molecular descriptor encoding this property is the octanol-water partition coefficient $\mathrm{K}_{\mathrm{ow}}$ (and $\log \mathrm{K}_{\text {ow }}$ or also $\log \mathrm{P}$, when no further specifications are given), i.e., the partition coefficient between 1-octanol 
and water. In addition, the lipophilicity can be factorized in two main terms [32].

\section{Hansch-Fujita substituent constant \\ $\log \frac{P_{X}}{P_{H}}=\varphi \cdot \pi_{X}$}

hydrophobic

Where $P_{X}$ and $P_{H}$ are the partition coefficients of an $X$-substituted and unsubstituted compound, respectively; polarity is the hydrophobic constant of the substituent $X ; \varphi$ constant reflects the characteristics of the solvent system and is assumed equal to one for the octanolwater solvent system [33]. These hydrophobic substituent constants are commonly used in Hansch analysis to encode the lipophilic behavior of the substituents; the lipophilicity of the whole molecule is obtained by adding to the lipophilicity of the unsubstituted parent compound $\left(\log \mathrm{P}_{\mathrm{H}}\right)$ to the lipophilic contributions of the substituent.

$\log P($ molecule $)=\log P_{H}+\sum_{s=1}^{S} \pi_{X_{S}}$

(3)

Where $S$ is the number of substitution sites and $\boldsymbol{\pi}_{\boldsymbol{X}_{\boldsymbol{S}}}$ are the hydrophobic constants of the substituents in the molecule. Distinct values of the $\pi$ constants were defined for the aromatic and aliphatic compounds. The HanschFujita hydrophobic constants are still widely used in QSAR studies, but not for calculating $\log \mathrm{P}$ values.

\section{Moriguchi model based on surface area}

The Moriguchi formulation is a model for predicting the lipophilicity of compounds based on the solventaccessible surface area (SASA) generated by a solvent probe of radius $1.4 \AA$ and a set of parameters encoding hydrophilic effects of polar groups[34]

$\log P=-1.06+1.90 S A S$

(4)

$$
-1.00 \sum_{K} S_{H_{K}}
$$

$n=138 ; r^{2}=0.99 ; s=0.13 ; F=7284$
Where $S_{H}$ values are measures of the surface area of polar groups contributing negatively to $\log \mathrm{P}$ of the compounds. The latter parameters can be considered as fragmental correction factors whose values are derived separately for polar groups in aliphatic and aromatic systems.

Partition coefficients of quinoline, quinolone and their derivatives

The octanol-water partition coefficients for quinoline and quinolone compounds and their derivatives can be obtained from the computation of the solvation free energy according to (Eq. 5). The $\log \mathrm{P}$ values are calculated by means of the following relation:<smiles>[Z19][Y]1c2c(c(=O)c([R3])c([R4])n2[Z1])C([R16])=[Y]([R6])C1[R6]</smiles>

Figure 1. Structure of quinolone and its derivatives (PART A)<smiles>[R4]c1nc2c([R7])c([R4])c([R4])c([R4])c2c([R4])c1[R4]</smiles>

Figure 2. The structural template of quinoline (PART B)

Where $R$ is the gas constant and $T$ is the temperature. The solvation free energy is used to compute the partition coefficient based on (Eq. 5) and only the solvation free energies in water and 1octanol is needed to calculate $\log \mathrm{P}$.

Materials and mathematical methods The compounds discussed in this study consists of 20 types of quinolones derivatives with substitution at 1,2,3,5, 6,7 and 8 positions and quinoline 
compounds. The structure of quinolone compounds and their derivatives is showed in Table 1. The structure of quinoline compounds is showed in Table 7.

Experimental approaches require precise laboratory equipment and, are very costly and expensive. Moreover, such experiments take long time to be carried out. As a result, many researchers employ theoretical methods to calculate $\log \mathrm{P}$. A review of the earlier studies shows that QSAR is the most common method used for this purpose. The earlier studies have proven that QSAR is an effective and relatively precise method for calculating $\log \mathrm{P}$, but it has its drawbacks too. Specifically, it requires a long process to be implemented. Some descriptors should be first determined and then modeling is done using the statistical methods. In this research, however, we have chosen the SCRFPCM model, because it is simple, quick and accurate. Furthermore, Henry's constant is directly related to the solvation free energy:

$K(\rho, T)=R T \rho \exp \left(\frac{\Delta G_{\text {sol }}}{R T}\right)$

Where $\rho$ is the density of the pure solvent, which is equal to that in the limit of infinite dilution. We have selected quinolone and quinoline compounds that have important clinical activit.

Table 1. Structure of quinolone and its derivatives (PART A)

\begin{tabular}{|c|c|c|c|c|c|c|c|c|c|}
\hline Compound & $\mathbf{R}_{1}$ & $\mathbf{R}_{2}$ & $\mathbf{R}_{3}$ & $\mathbf{R}_{5}$ & $\mathbf{R}_{6}$ & $\mathbf{R}_{7}$ & $\mathbf{R}_{8}$ & $\mathbf{X}$ & $\mathbf{Y}$ \\
\hline Grepafloxacin & & $\mathrm{H}$ & $\mathrm{COOH}$ & $\mathrm{CH}_{3}$ & $\mathrm{~F}$ & & $\mathrm{H}$ & $\mathrm{C}$ & $\mathrm{C}$ \\
\hline Sparfloxacin & & $\mathrm{H}$ & $\mathrm{COOH}$ & $\mathrm{NH}_{2}$ & $\mathrm{~F}$ & & $\mathrm{~F}$ & $\mathrm{C}$ & $\mathrm{C}$ \\
\hline Gemifloxacin & & $\mathrm{H}$ & $\mathrm{COOH}$ & $\mathrm{H}$ & $\mathrm{F}$ & & - & $\mathrm{N}$ & $\mathrm{C}$ \\
\hline Levofloxacin & $* * *$ & $\mathrm{H}$ & $\mathrm{COOH}$ & $\mathrm{H}$ & $\mathrm{F}$ & & $* * *$ & $\mathrm{C}$ & $\mathrm{C}$ \\
\hline Moxifloxacin & & $\mathrm{H}$ & $\mathrm{COOH}$ & $\mathrm{H}$ & $\mathrm{F}$ & & $\mathrm{OCH}_{3}$ & $\mathrm{C}$ & $\mathrm{C}$ \\
\hline Nalidixic acid & Et & $\mathrm{H}$ & $\mathrm{COOH}$ & $\mathrm{H}$ & $\mathrm{H}$ & $\mathrm{CH}_{3}$ & - & $\mathrm{N}$ & $\mathrm{C}$ \\
\hline Ciprofloxacin & & $\mathrm{H}$ & $\mathrm{COOH}$ & $\mathrm{H}$ & $\mathrm{F}$ & & $\mathrm{H}$ & $\mathrm{C}$ & $\mathrm{C}$ \\
\hline Pefloxacin & Et & $\mathrm{H}$ & $\mathrm{COOH}$ & $\mathrm{H}$ & $\mathrm{F}$ & & $\mathrm{H}$ & $\mathrm{C}$ & $\mathrm{C}$ \\
\hline Fleroxacin & $\mathrm{CH}_{2} \mathrm{CH}_{2} \mathrm{~F}$ & $\mathrm{H}$ & $\mathrm{COOH}$ & $\mathrm{H}$ & $\mathrm{F}$ & & $\mathrm{F}$ & $\mathrm{C}$ & $\mathrm{C}$ \\
\hline Pipemidic acid & Et & $\mathrm{H}$ & $\mathrm{COOH}$ & $\mathrm{H}$ & - & & - & $\mathrm{N}$ & $\mathrm{N}$ \\
\hline
\end{tabular}




\begin{tabular}{|c|c|c|c|c|c|c|c|c|c|}
\hline Enoxacin & Et & $\mathrm{H}$ & $\mathrm{COOH}$ & $\mathrm{H}$ & $\mathrm{F}$ & $\xi-\mathbf{N} \mathbf{N H}$ & - & $\mathrm{N}$ & $\mathrm{C}$ \\
\hline Lomefloxacin & $\mathrm{Et}$ & $\mathrm{H}$ & $\mathrm{COOH}$ & $\mathrm{H}$ & $\mathrm{F}$ & $\xi-\mathbf{N} \mathbf{N H}$ & $\mathrm{F}$ & $\mathrm{C}$ & $\mathrm{C}$ \\
\hline Ofloxacin & $* * *$ & $\mathrm{H}$ & $\mathrm{COOH}$ & $\mathrm{H}$ & $\mathrm{F}$ & $\xi \mathbf{N} \mathbf{N}-$ & $* * *$ & $\mathrm{C}$ & $\mathrm{C}$ \\
\hline Norfloxacin & Et & $\mathrm{H}$ & $\mathrm{COOH}$ & $\mathrm{H}$ & $\mathrm{F}$ & $\xi-\mathbf{N H}$ & $\mathrm{H}$ & $\mathrm{C}$ & $\mathrm{C}$ \\
\hline $\begin{array}{c}*= \\
\xi-\mathbf{C} \\
\xi \\
\xi\end{array}$ & & & & & & & & & \\
\hline
\end{tabular}

\section{Results and discussion}

\section{Calculations}

The geometry of the molecules used here was fully optimized using DFT (B3LYP) and Hartree-Fock (HF) calculations with the $6-31++\mathrm{G}^{* *}$ basis set in the Gaussian 09 package [35-37]. Various properties of the compounds were calculated with DFT-B3LYP and HF methods and two basis sets 6-31G, 6-31++G** [38,39]. These basis sets were selected because they provide information about the relative importance of diffuse $(+)$ and polarization (*) functions. In the basis set 6-31, the inner layer function is written as a linear combination of three initial Gaussian functions, and the capacity layer functions are divided into two and one Gaussian functions. Because atomic orbitals are deformed when molecules are formed, to apply the effects of such a polarity, basic functions with different angular momentum values are added from the base state. The use of a star $(*)$ increases the orbit of the type (d) for heavy atoms. Moreover, the use of two stars (**) adds an orbital type (d) to heavy atoms and (p) type orbits for the hydrogen atom. To better describe systems with non-bonded electron pairs and generally the systems with wider electron diffusion, diffused base functions are used. The basis set 6$31++\mathrm{G}$ adds the first and second rotational atoms to hydrogen atoms as well as a set of diffused (s,p) orbits. Polarized functions can be used with diffused functions. In this case, we will have the basis sets of $6-31++G^{* *}$ and $6-$ $31 \mathrm{G}$.

The larger basis sets were not used because calculations by these sets needed unacceptably long time. After the geometry optimization of the compounds was performed, the solvation free energy was calculated using the PCM solvation model. The Gibbs solvation free energies of the compounds in water and 1-octanol solvents were calculated based on the DFT-B3LYP and HF methods. The values of solvation free energies have been reported in Table 2 . 
Table 2. The Gibbs solvation free energy $\left(\Delta G_{\text {sol }}, \mathrm{kcal} / \mathrm{mol}\right)$ in water and 1-octanol solvents based on HF/6$31++\mathrm{G}^{* *}$ and B3LYP/6-31++G** calculations.

\begin{tabular}{|c|c|c|c|c|}
\hline Compound & $\begin{array}{c}\Delta \mathbf{G}_{\text {sol }}(\text { water }) \\
\left(\mathbf{H F} / 6-31++\mathbf{G}^{* *}\right)\end{array}$ & $\begin{array}{c}\Delta \mathbf{G}_{\text {sol }}(\text { octanol }) \\
(\mathbf{H F} / 6- \\
\text { 31++G**) } \\
\end{array}$ & $\begin{array}{c}\mathbf{G}_{\text {sol }} \text { (water) } \\
\text { (B3LYP/6- } \\
\text { 31++G**) } \\
\end{array}$ & $\begin{array}{c}\mathbf{G}_{\text {sol }}(\text { octanol) } \\
\text { (B3LYP/6- } \\
\text { 31++G**) } \\
\end{array}$ \\
\hline Primaquine & -10.47 & -11.29 & -8.83 & -9.92 \\
\hline Quinidine & -10.30 & -13.51 & -8.18 & -11.83 \\
\hline Quinine & -10.17 & -13.85 & -8.18 & -11.83 \\
\hline Chloroquine & -5.59 & -9.94 & -4.12 & -8.74 \\
\hline Cinchocaine & -13.51 & -17.97 & -8.15 & -13.22 \\
\hline Imiquimod & -10.04 & -12.55 & -8.05 & -10.85 \\
\hline Grepafloxacin & -19.2 & -21.3 & -17.02 & -19.51 \\
\hline Sparfloxacin & -18.31 & -21.4 & -15.51 & -19.01 \\
\hline Levofloxacin & -23.95 & -24.52 & -18.55 & -19.78 \\
\hline Moxifloxacin & -19.87 & -21.47 & -16.92 & -19.53 \\
\hline Nalidixic acid & -14.15 & -15.41 & -11.98 & -13.51 \\
\hline Ciprofloxacin & -25.08 & -25.02 & -22.25 & -22.57 \\
\hline Pefloxacin & -16.88 & -18.83 & -14.37 & -16.66 \\
\hline Fleroxacin & -21.84 & -22.8 & -18.52 & -19.95 \\
\hline Pipemidic acid & -23.88 & -24 & -20.51 & -20.89 \\
\hline Enoxacin & -33.69 & -32.35 & -28.46 & -27.89 \\
\hline Lomefloxacin & -19.72 & -25.61 & -16.71 & -18.9 \\
\hline Ofloxacin & -23.7 & -24 & -19.94 & -21.24 \\
\hline Norfloxacin & -24.9 & -24.39 & -31.84 & -30.78 \\
\hline Gemifloxacin & -23.58 & -26.05 & -20.27 & -23.18 \\
\hline
\end{tabular}

On the other hand, the free energy of cavity formation $(\mathrm{kcal} / \mathrm{mol})$ in water for the compounds determined by DFT
(B3LYP) and HF calculations are shown in Table.

Table 3. Cavity formation energy ( $\mathrm{kcal} / \mathrm{mol})$ calculated using different computational methods for the compounds and their surface area and volume.

\begin{tabular}{|c|c|c|c|c|}
\hline Compound & $\begin{array}{c}\Delta \mathbf{G}_{\text {cav }}(\text { B3LYP/6- } \\
\text { 31++G**) }\end{array}$ & $\begin{array}{c}\Delta \mathbf{G}_{\mathrm{cav}}(\mathbf{H F} / \mathbf{6}- \\
\left.31++\mathbf{G}^{* *}\right)\end{array}$ & $\begin{array}{l}\text { Surface Area } \\
\text { (Hyperchem) }\end{array}$ & $\begin{array}{c}\text { Volume } \\
\text { (Hyperchem) }\end{array}$ \\
\hline Primaquine & 34.24 & 34.22 & 462.55 & 847.88 \\
\hline Quinidine & 39.84 & 39.82 & 428.16 & 951.81 \\
\hline Quinine & 39.74 & 39.72 & 423.73 & 951.28 \\
\hline Chloroquine & 42.01 & 41.99 & 570.87 & 1005.12 \\
\hline Cinchocaine & 47.34 & 47.33 & 658.9 & 1151.93 \\
\hline Imiquimod & 31.24 & 31.23 & 357.98 & 735.65 \\
\hline Grepafloxacin & 41.52 & 41.52 & 483.37 & 978.75 \\
\hline Sparfloxacin & 44.26 & 44.26 & 480.8 & 1019.88 \\
\hline Levofloxacin & 39.91 & 39.91 & 466.17 & 944.95 \\
\hline Moxifloxacin & 47.34 & 47.34 & 446.73 & 1040.6 \\
\hline Nalidixic acid & 28.64 & 28.64 & 365.45 & 669.48 \\
\hline Ciprofloxacin & 36.98 & 36.96 & 421.34 & 883.98 \\
\hline Pefloxacin & 38.51 & 38.49 & 475.9 & 894.9 \\
\hline Fleroxacin & 40.41 & 40.41 & 496.95 & 926.68 \\
\hline Pipemidic acid & 34.29 & 34.27 & 420.09 & 822.1 \\
\hline Enoxacin & 36.73 & 36.73 & 422.04 & 834.97 \\
\hline Lomefloxacin & 39.95 & 39.93 & 472.06 & 921.21 \\
\hline Ofloxacin & 40.14 & 40.14 & 466.84 & 945.57 \\
\hline Norfloxacin & 37.95 & 35.97 & 445.78 & 859.81 \\
\hline Gemifloxacin & 44.8 & 44.8 & 496.69 & 1031.15 \\
\hline
\end{tabular}


Here, the cavity formation energy as an important part of solvation free energy was calculated using the PCM model at the B3LYP and HF levels with the 6$31++\mathrm{G}^{* *}$ basis set. A cooperation between $\Delta \mathrm{G}_{\mathrm{cav}}$ and surface area and volume shows that the $\Delta \mathrm{G}_{\mathrm{cav}}$ is often high for big structure compounds and low for small compounds. Therefore, the interaction between solvent and solute sometimes results in the lower $\Delta \mathrm{G}_{\text {cav }}$ for the large compounds. Henry's constants were also calculated based on Eq. 6 using the solvation free energies in Table 2. The calculated values are given in Table 4.

Table 4. Henry's constant (atm.kg/mol) and solvation free energy determined from $\left(\mathrm{HF} / 6-31++\mathrm{G}^{* *}\right)$ and (B3LYP/6-31++G**) calculations

\begin{tabular}{|c|c|c|c|c|}
\hline Compound & $\begin{array}{c}\Delta \mathbf{G}_{\text {sol }}(\text { water) } \\
\text { HF/6-31++G** }\end{array}$ & $\begin{array}{c}\mathrm{K}(\rho, \mathrm{T}) \\
\mathrm{HF} / 6-31++\mathrm{G}^{* *}\end{array}$ & $\begin{array}{c}\Delta \mathbf{G}_{\text {sol }}(\text { water }) \\
\text { B3LYP/6-31++G** }\end{array}$ & $\begin{array}{c}\text { K }(\rho, T) \\
\text { B3LYP/6-31++G** }\end{array}$ \\
\hline Primaquine & -10.47 & $5.16230^{*} * 10^{-7}$ & -8.83 & $8.22439 * 10^{-6}$ \\
\hline Quinidine & -10.30 & $6.87810^{*} 10^{-7}$ & -4.12 & $2.33311 * 10^{-2}$ \\
\hline Quinine & -10.17 & $8.56583 * 10^{-7}$ & -8.18 & $2.46382 * 10^{-5}$ \\
\hline Chloroquine & -5.59 & $1.95119 * 10^{-3}$ & -4.12 & $2.33311 * 10^{-2}$ \\
\hline Cinchocaine & -13.51 & $3.04975^{*} 10^{-9}$ & -8.15 & $2.59180 * 10^{-5}$ \\
\hline Imiquimod & -10.04 & $1.06676^{*} 10^{-6}$ & -8.05 & $3.06839 * 10^{-5}$ \\
\hline Grepafloxacin & -19.20 & $2.05637 * 10^{-13}$ & -17.02 & $8.15114 * 10^{-12}$ \\
\hline Sparfloxacin & -18.31 & $9.23729 * 10^{-13}$ & -15.51 & $1.04272 * 10^{-10}$ \\
\hline Levofloxacin & -23.95 & $6.77595 * 10^{-17}$ & -18.55 & $6.16035^{*} 10^{-13}$ \\
\hline Moxifloxacin & -19.87 & $6.63650 * 10^{-14}$ & -16.92 & $9.64998 * 10^{-12}$ \\
\hline Nalidixic acid & -14.15 & $1.03552 * 10^{-9}$ & -11.98 & $4.03593 * 10^{-8}$ \\
\hline Ciprofloxacin & -25.08 & $1.00598 * 10^{-17}$ & -22.25 & $1.19455^{*} 10^{-15}$ \\
\hline Pefloxacin & -16.88 & $1.03240 * 10^{-11}$ & -14.37 & $7.14302 * 10^{-10}$ \\
\hline Fleroxacin & -21.84 & $2.38655 * 10^{-15}$ & -18.52 & $6.48034 * 10^{-13}$ \\
\hline Pipemidic acid & -23.88 & $7.62581 * 10^{-17}$ & -20.51 & $2.25303 * 10^{-14}$ \\
\hline Enoxacin & -33.69 & $4.90644 * 10^{-24}$ & -28.46 & $3.34793 * 10^{-20}$ \\
\hline Lomefloxacin & -19.72 & $8.54872 * 10^{-14}$ & -16.71 & $1.37554 * 10^{-11}$ \\
\hline Ofloxacin & -23.70 & $1.03333 * 10^{-16}$ & -19.94 & $5.89689 * 10^{-14}$ \\
\hline Norfloxacin & -24.9 & $1.36315 * 10^{-17}$ & -31.84 & $1.11420 * 10^{-22}$ \\
\hline Gemifloxacin & -23.58 & $1.26534 * 10^{-16}$ & -20.27 & $3.37836 * 10^{-14}$ \\
\hline
\end{tabular}

Henry's constant decreases with an increase in the absolute value of solvation free energy in water according to both B3LYP and HF calculations with the $6-31++\mathrm{G}^{* *}$ basis set. The solvation free energy was calculated based on the
B3LYP and HF methods with different basis sets, and the $\log \mathrm{P}$ was found based on Eq. 5. These values and the partition coefficients from the Hyperchem software and other methods from different papers are given in Table 5 .

Table 5. The $\log P$ values calculated using two methods and two basis sets with the values obtained from the Hyperchem (QSAR properties) and other methods reported in different studies and experimental data.

\begin{tabular}{cccccccc}
\hline Compound & HF/ & HF/ & B3LYP/6- & B3LYP/ & Hyperchem & $\begin{array}{c}\text { Other } \\
\text { methods }\end{array}$ & $\begin{array}{c}\text { Experimental } \\
\text { data }\end{array}$ \\
\hline Primaquine & 0.44 & 0.60 & 1.21 & 1.79 & 1.28 & $1.64 \mathrm{a}$ & $2.10 \mathrm{a}$ \\
Quinidine & 1.45 & 2.34 & 2.11 & 2.67 & 2.37 & $2.51 \mathrm{a}$ & $3.44 \mathrm{~b}$ \\
Quinine & 1.97 & 2.70 & 2.21 & 2.67 & 2.36 & $2.71 \mathrm{a}$ & $3.44 \mathrm{~b}$ \\
Chloroquine & 2.89 & 3.19 & 2.98 & 3.39 & 3.61 & $3.93 \mathrm{a}$ & $4.63 \mathrm{a}$ \\
Cinchocaine & 1.70 & 3.27 & 2.59 & 3.72 & 2.73 & $3.70 \mathrm{a}$ & $4.40 \mathrm{a}$ \\
Imiquimod & 1.07 & 1.84 & 1.91 & 2.05 & 2.18 & $2.65 \mathrm{a}$ & $2.70 \mathrm{a}$ \\
Grepafloxacin & 0.70 & 1.54 & 1.21 & 1.80 & 5.54 & $0.12 \mathrm{a}$ & $2.90 \mathrm{~g}$ \\
Sparfloxacin & 1.51 & 2.26 & 1.68 & 2.56 & 5.02 & $-0.04 \mathrm{a}$ & $2.50 \mathrm{c}$ \\
Levofloxacin & 0.11 & 0.41 & 0.70 & 0.90 & 4.77 & $0.65 \mathrm{a}$ & $2.10 \mathrm{c}$ \\
Moxifloxacin & 0.80 & 1.17 & 1.39 & 1.91 & 5.11 & $-0.50 \mathrm{a}$ & $2.03 \mathrm{f}$ \\
Nalidixic acid & 0.51 & 0.92 & 0.70 & 1.12 & 4.93 & $1.00 \mathrm{a}$ & $1.59 \mathrm{~d}$
\end{tabular}




\begin{tabular}{|c|c|c|c|c|c|c|c|}
\hline Ciprofloxacin & -0.12 & -0.04 & 0.95 & 0.23 & 4.81 & $-0.81 \mathrm{a}$ & $0.28 \mathrm{c}$ \\
\hline Pefloxacin & 1.70 & 1.43 & 2.10 & 1.68 & 5.12 & $0.88 \mathrm{a}$ & $0.27 \mathrm{c}$ \\
\hline Fleroxacin & 0.84 & 0.70 & 1.10 & 1.04 & 5.19 & $2.30 \mathrm{a}$ & $0.24 \mathrm{e}$ \\
\hline $\begin{array}{l}\text { Pipemidic } \\
\text { acid }\end{array}$ & 0.10 & 0.08 & 0.51 & 0.27 & 3.40 & $-1.50 \mathrm{a}$ & $0.18 \mathrm{f}$ \\
\hline Enoxacin & -1.57 & -0.98 & -0.75 & -0.41 & 4.43 & $-0.98 \mathrm{a}$ & $-0.20 \mathrm{a}$ \\
\hline Lomefloxacin & 3.76 & 4.30 & 2.01 & 1.60 & 5.42 & $-0.39 a$ & $-0.30 \mathrm{~h}$ \\
\hline Ofloxacin & 0.50 & 0.22 & 1.32 & 0.95 & 4.77 & $0.65 \mathrm{a}$ & $-0.39 \mathrm{i}$ \\
\hline Norfloxacin & -0.52 & -0.37 & -0.63 & -0.77 & 4.76 & $-2.92 \mathrm{a}$ & $-1.03 \mathrm{e}$ \\
\hline Gemifloxacin & 1.70 & 1.81 & 1.43 & 2.13 & 4.25 & $0.92 \mathrm{a}$ & $2.30 \mathrm{c}$ \\
\hline
\end{tabular}

A column in Table 5 shows the $\log \mathrm{P}$ values calculated using the Hyperchem program. This program was used to calculate the following parameters from the energy minimized structures, molecular surface area, mass volume, polarizability, molar refractivity, and $\log \mathrm{P}$. Another column in this Table includes the $\log \mathrm{P}$ values of the compounds calculated using different programs and methods.

Based on the data shown in Figures 35 , the values calculated at the HF/6$31++\mathrm{G}^{* *}$ and B3LYP/6-31++G** levels of theory were closer to the experimental data than those calculated using the HF/6-31G and B3LYP/6-31G methods, Hyperchem software, and other methods presented in different paper.

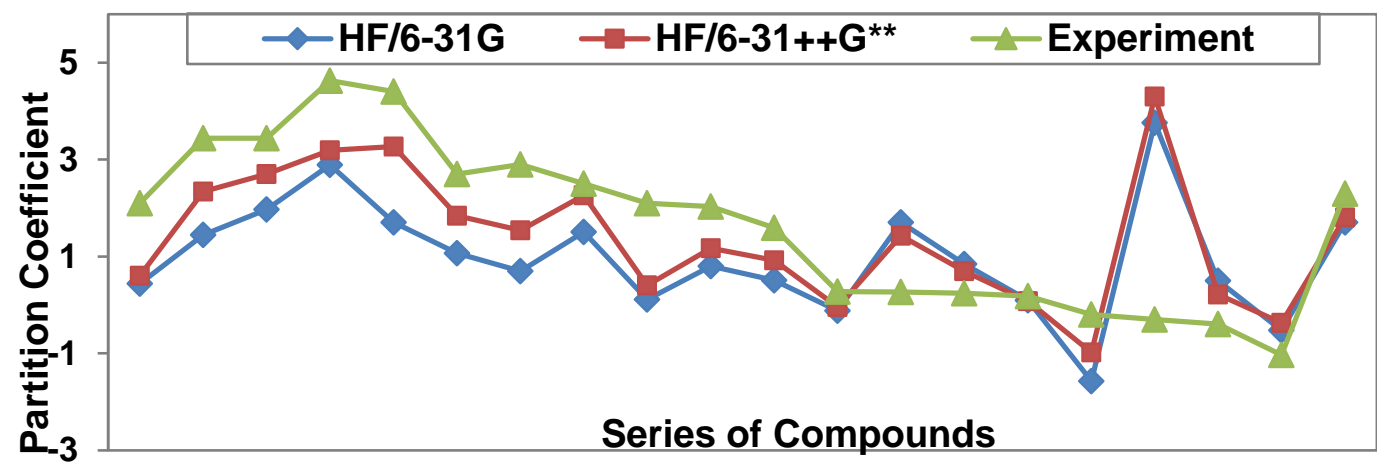

Figure 3. Comparison between values of partition coefficient from experiment and HF calculations with different basis sets

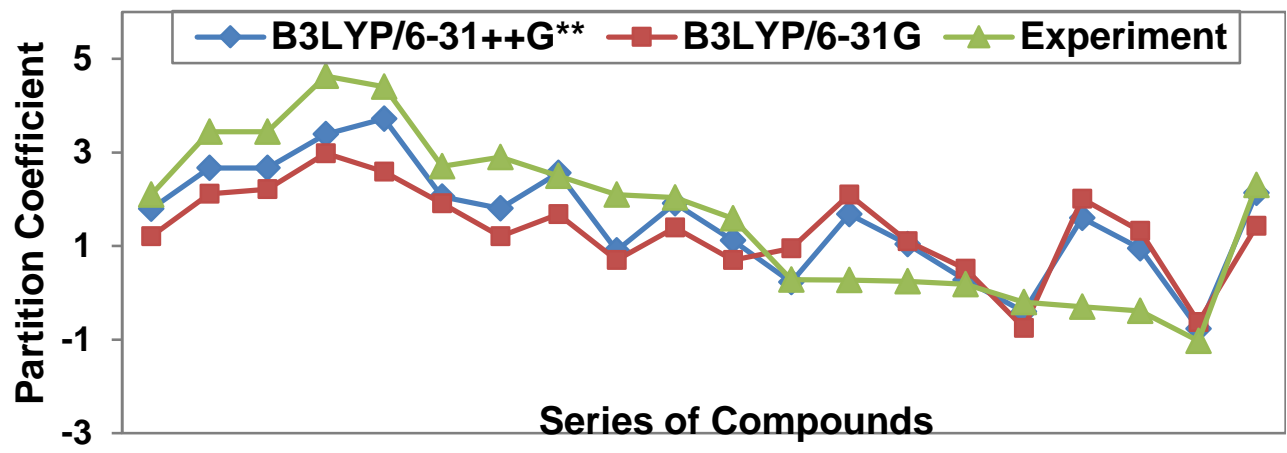

Figure 4. Comparison between values of partition coefficient from experiment and B3LYP calculations with different basis sets 


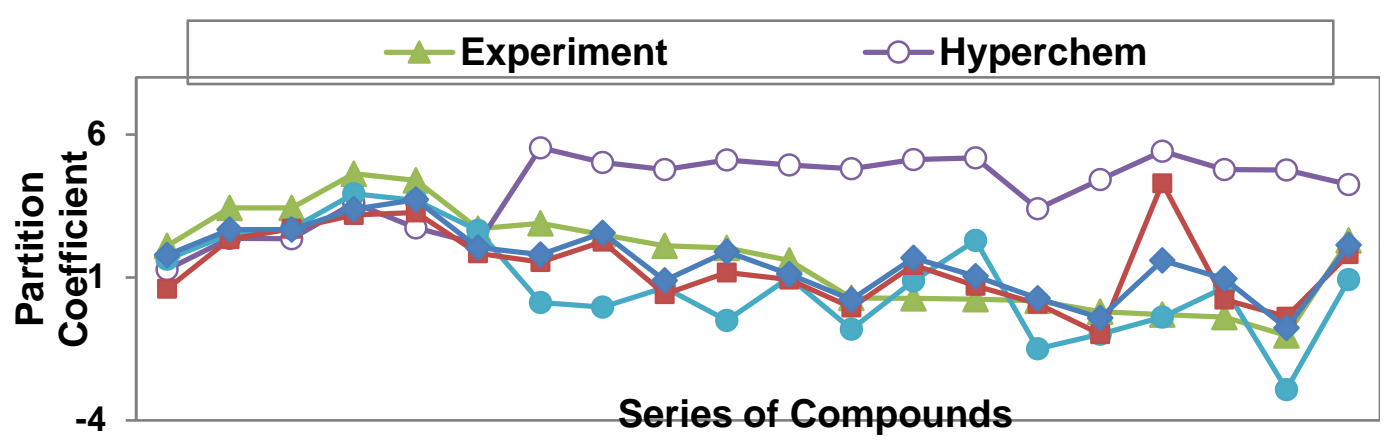

Figure 5. Comparison between values of partition coefficients from HF/6-31++G** and B3LYP/6$31++\mathrm{G}^{* *}$ with the experimental data, QSAR properties of Hyperchem, and other method

Since $\log P$ values depend on the interaction between solvent and the compounds, and quantum mechanical methods describe electrostatic intermolecular interactions very well, the agreement with the experiment was quite satisfactory. The $\log \mathrm{P}$ values calculated in the earlier studies were usually based on the QSAR method [49-51]. The method needs time-consuming computations and modeling of different properties of the molecules. Therefore, the QSAR approach consumes long times and calculations, while the estimation of the $\log \mathrm{P}$ from the solvation free energy as implemented in this study is fast and uncomplicated. It was shown that we can obtain $\log \mathrm{P}$ by calculating only the solvation free energies in water and octanol solvents. The polarizability of a molecule is a measure of the degree to which the electron density distribution of the molecule can be distorted by an applied electric field. The attractive part of the Van Der Waals interaction is a good measure for the polarizability. Highly polarizable molecules are expected to be strongly attracted by other molecules. The polarizability of a molecule can also enhance the solubility in water. Indeed, the polarizability is a function of atomic mass.

Table 6 shows the electronic parameters of the compounds that were calculated using the HF method with the $6-31++\mathrm{G}^{* *}$ basis set. As expected, the data showed that the $\log \mathrm{P}$ values decrease with a decrease in the polarizability, mass, volume and surface area. This type of logical relationship was observed for both the $\mathrm{HF}$ and B3LYP methods.

Table 6. The electronic parameters of quinolone, fluoroquinolone, and quinoline compounds according to the HF/6-31++G** calculations using the Hyperchem software.

\begin{tabular}{cccccccc}
\hline Compound & $\mathbf{S A}, \AA^{\mathbf{2}}$ & $\mathbf{V}, \AA^{\mathbf{3}}$ & $\begin{array}{c}\mathbf{H E}, \\
\mathbf{k c a l . m o l}^{\mathbf{1}}\end{array}$ & $\mathbf{R}_{\mathbf{f}, \AA^{\mathbf{3}}}$ & $\boldsymbol{\alpha}, \AA^{\mathbf{3}}$ & $\mathbf{m}, \mathbf{a m u}$ & $\mathbf{L o g P}$ \\
\hline Primaquine & 462.55 & 847.88 & -8.96 & 42.60 & 30.26 & 259.35 & 1.28 \\
Quinidine & 428.16 & 951.81 & -5.50 & 56.42 & 36.98 & 324.42 & 2.37 \\
Quinine & 423.73 & 951.28 & -5.18 & 52.97 & 36.98 & 324.42 & 2.36 \\
Chloroquine & 570.87 & 1005.12 & -0.82 & 60.24 & 37.05 & 319.88 & 3.61 \\
Cinchocaine & 658.90 & 1151.93 & -3.96 & 82.14 & 40.68 & 349.52 & 2.73 \\
Imiquimod & 357.98 & 735.65 & -6.50 & 30.97 & 27.94 & 240.31 & 2.18 \\
Grepafloxacin & 483.37 & 978.75 & -7.86 & 59.47 & 36.55 & 359.40 & 5.54 \\
Sparfloxacin & 480.80 & 1019.88 & -10.74 & 62.51 & 37.81 & 392.41 & 5.02 \\
Levofloxacin & 466.17 & 944.95 & -7.32 & 57.40 & 35.35 & 361.37 & 4.77 \\
Moxifloxacin & 446.73 & 1040.60 & -7.76 & 68.68 & 40.08 & 401.44 & 5.11 \\
Nalidixic acid & 365.45 & 669.48 & -7.84 & 27.86 & 23.76 & 232.24 & 4.93 \\
Ciprofloxacin & 421.34 & 883.98 & -9.76 & 50.44 & 32.88 & 331.35 & 4.81
\end{tabular}




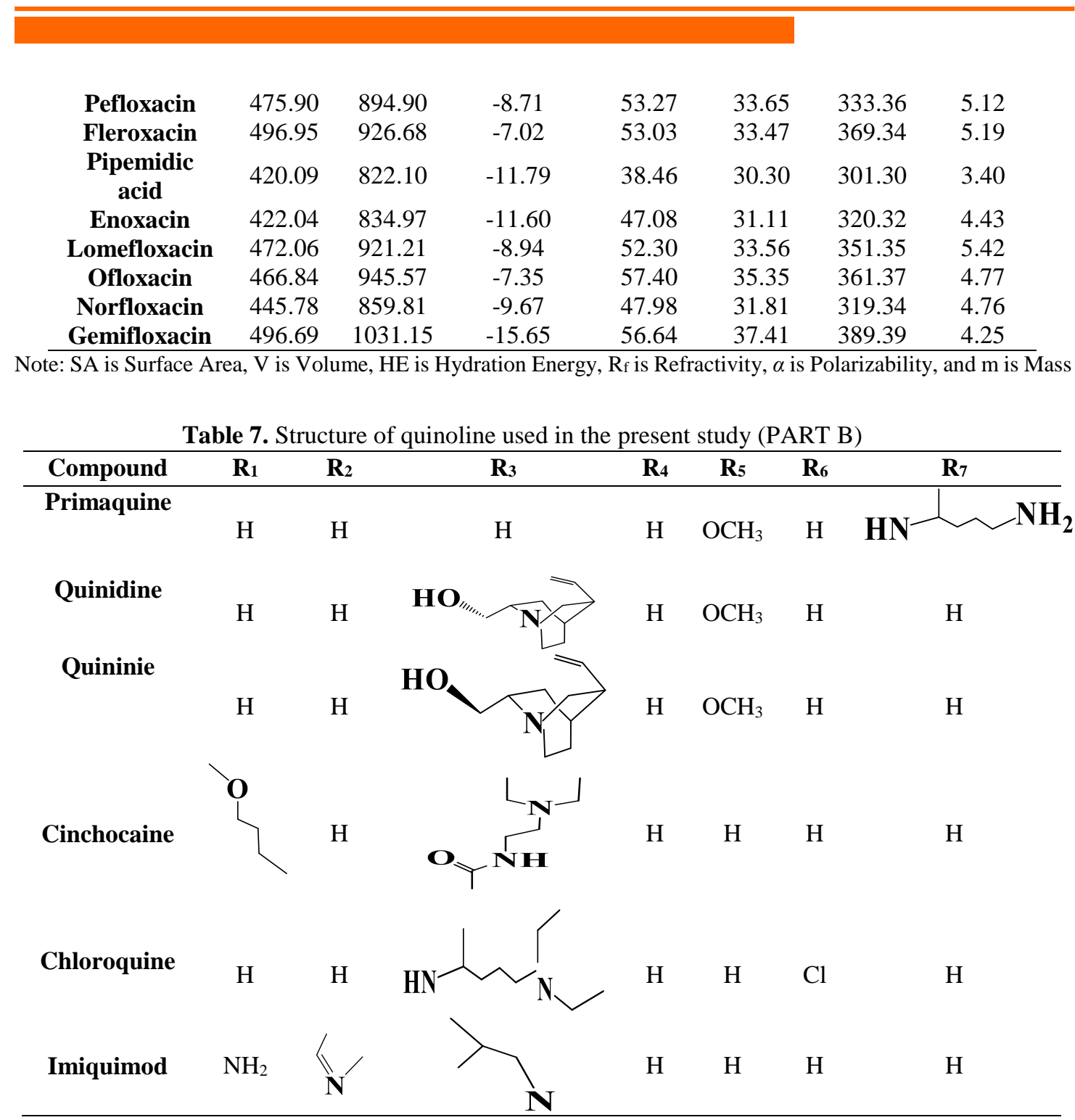

\section{Conclusion}

In this research, we have applied $\mathrm{Ab}$ initio and DFT computational methods to the calculation of some important thermodynamic properties including the solvation free energy in the two solvents (organic and aqueous). The calculations began with the geometry optimization of the drug molecules using the DFT and Hartree-Fock methods. Then, the solvation free energy of the compounds was obtained for the water and 1-octanol solvents based on HF and B3LYP estimates using two basis sets. The solvation free energy (in 1-octanol) of the investigated compounds became more negative in the presence of electron-donor groups. At the next step, the $\log \mathrm{P}$ was calculated using the solvation free energy data. As it was mentioned, the $\log \mathrm{P}$ is an important pharmaceutical index of quinoline and quinolone derivatives. There are several theoretical methods for calculating $\log \mathrm{P}$ with high accuracy, but the problem with most of them is that they require demanding computations and long times. Moreover, the application of such methods in calculating the partition coefficient in different solvents is difficult, while calculating the solvation free energy in any solvent using the quantum mechanics approach is possible. Eventually, the partition coefficient can also be calculated using the method employed in this study in 
every environment. The results in Table 5 showed that the computed values of $\log \mathrm{P}$ in octanol/water using this approach were noticeably closer to experimental values compared to similar data from the literature. Actually, the errors between the results of our study and the experimental values were insignificant. Moreover, $\log \mathrm{P}$ was computed using DFT and HF methods with two basis sets. Overall, the results showed that B3LYP/6-31++G** could provide closer estimates to the experimental values compared to the other methods. The proper description of the structures needed polarization functions in the basis set, while the addition of diffuse functions did not significantly affect the results. Finally, factors such as refractivity and polarizability were connected with the interactions between the solute and solvent, thus rendering as influencing factors that should be taken into consideration when studying $\log \mathrm{P}$ values.

\section{Acknowledgements}

The authors would like to thank Islamic Azad University of Arak for their support on this work.

\section{References}

[1] S. Richter, C. Parolin , M. Palumbo,G. Palu, Curr Drug Targets Infect Disord., 2004, 4, 111-116.

[2] A. Dalhoff , F.J. Schmitz, Eur J Clin Microbiol Infect Dis., 2003, 22, 203-221. [3] V. Ricci, L. Piddock, Antimicrob. Age. Chemother., 1998, 42, 2956-2960.

[4] S. Heeb, M.P. Fletcher, S.R. Chhabra and et al, FEMS Microbiol Rev., 2011, 35, 247-274.

[5] M. M. Neuhauser, R.A. Weinstein, R. Rydman and et al. JAMA., 2003, 289, 885-888.

[6] H. Liu, S.G. Mulholland, Am J Med., 2005, 118, 14S-20S.

[7] T. Lewis, J. Cook, J Athl Train., 2014, 49, 422-427.
[8] D.C. Hooper, Emerg Infect Dis., 2001, 7, 337-341.

[9] J.A. Katie, J.K. Robert, O. Neil, Biochemistry., 2014, 53, 1565-1574.

[10] A.H. Abadi, G.H. Hegazy, A.A.E. Zaher, Bioorg. Med. Chem., 2005, 13, 5759-5765.

[11] B.N. Acharya, D. Thavaselvam, M.B. Kaushik, Med. Chem. Res., 2008, 17, 487-494.

[12] H. Assefa, S. Kamath, J.K. Buolamwini, J. Comput. Aided Mol. Des., 2003, 17, 475-493.

[13] A.P. Gorka, A. Dios, P.D. Roepe, $J$ Med Chem., 2013, 56, 5231-5246.

[14] M. Shiri, M.M. Heravi, H. Hamidi, M.A. Zolfigol, Z. Tanbakouchian, JICS., 2016, 13, 2239-2246.

[15] Y. Kwon, Partition and Distribution Coefficients, 2001. Kluwer Academic/Plenum, New York.

[16] W. Lewgowd, A. Stanczaka, Z. Ochocki, K. Rzeszowska-Modzelewska, Acta Pol Pharm., 2007, 64, 195-200.

[17] D. Cronin, T. Mark, Current Computer-Aided Drug Design., 2006, 2 , 405-413.

[18] J. Sangster, Octanol-Water Partition Coefficients: Fundamentals and Physical Chemistry, 1997. John Wiley \& Sons, Chichester.

[19] L. Shargel, W.P. Susanna, A.B. Yu, Physiological Drug Distribution and Protein Binding". Applied Biopharmaceutics \& Pharmacokinetics, 2012. McGraw-Hill, New York.

[20] M.A. Cabrera Perez, H. Gonzalez Diaz, C. Fernandez Teruel, J.M. Pela Delfina, M. Bermejo Sanz, Eur J Pharm Biopharm., 2002, 53, 317-325.

[21] C. Nieto-Draghi, G. Fayet, B. Creton and et al, Chem Rev., 2015, 24, 13093-13164.

[22] D.J. Abraham, Burger's medicinal chemistry and drug discovery, 2003. John Wiley \& Sons, New Jersey.

[23] Z. Bayat, J. Movaffagh, J Phys Chem A., 2010, 84, 2293-2299. 
[24] C. Duda-Seiman , R.A. Hughes, R. Nuniu, D. Ciubotariu , N. Suceveanu, $J$ Med Pharm., 2004, 144-149.

[25] C. Duda-Seiman , D. Duda-Seiman, M.V. Putz, D. Ciubotariu, Digest Journal of Nanomaterials and Biostructures., 2007, 2, 207-219.

[26] C. Duda-Seiman , D. Duda-Seiman, D. Dragos, M. Medeleanu, V. Careja, M. V. Putz, A.M. Lacrama, A. Chiriac, R. Nutiu, D. Ciubotariu, Int J Mo Sci., 2006, 7, 537-555.

[27] W.L. Jorgensen, E.M. Duffy, $A d v$ Drug Deliv Rev., 2002, 54, 355-366.

[28] F. Kobarfard, A. Khalaj , F. Daryaei, Z. Ardeshir Larijany, S. Rezaei, J Pharm Sci., 2008, 16, 55-59.

[29] M. Haeberlein , T. Brinck , J Chem Soc Perkin Trans., 1997, 2, 289-294.

[30] H. Chuman, A. Mori, H. Tanaka, Anal Sci., 2002, 18, 1015- 1020.

[31] P.J. Taylor, in: C.A. Ramsden (ed), Quantitative drug design, 1990. Pergamon Press, Oxford.

[32] Reviews in Computational Chemistry (Eds K.B. Lipkowitz, D. Boyd), 1997. Wiley-VCH, New York. [33] C. Hansch, T. Fujita, J Am Chem Soc., 1964, 86, 1616-1626.

[34] I. Moriguchi, Chem Pharm Bull., 1975, 23, 247-257.

[35] C.C.J. Roothaan, Rev. Mod. Phys., 1951, 23, 69-89.

[36] M.J. Frisch, G.W. Trucks, H.B. Schlegel, G.E. Scuseria, M.A. Robb, J.A. Pople, Gaussian, Inc., Wallingford CT 2009.

[37] S.H. Hussein-Mohamed, A.A. Sayed, J. Chem. Rev., 2019, 1, In press;
[38] M. Islam, A. Kumer, N. Sarker, S. Paul, A. Zannat, Adv. J. Chem. A., 2019, 2, 316-326.

[39] Z. Javanshir, S. Jameh-Bozorghi, P. Peyki, Adv. J. Chem. A., 2018, 1, 117126.

[40] Drugbank [https://www. drugbank. ca/drugs/ DB00365].

[41] A.V. Rudraraju, P.N.A. Amoyaw, T.J. Hubin, M.O. Faruk Khan, Pharmazie. 2014, 69, 655-662.

[42] R. Gayatri, C. Nagasuma, S. Narayanaswamy, Malar J., 2017, 16, 290-298.

[43] L.R. Danna, K.E. Steven, M.R. Christopher, Int J Pharm., 1992, 88, 379389.

[44] W. Schmitt, Toxicol in Vitro., 2008, 22, 457-467.

[45] M. Angeles, C. Sanchez, M. Rambla-Alegre, S. Carda-Broch, J. Esteve-Romero, J Liq Chromatogr Related Technol., 2010, 23, 513-525.

[46] H. Yamaguchi, I. Yano, H. Saito, K. Inui, J Pharmacol Exp Ther., 2002, 300, 1063- 1069.

[47] G. Szasz, Int J Pharm., 1992, 79, 8996.

[48] K. Takacs-Novak, A. Avdeef, $J$ Pharm Biomed Anal., 1996, 14, 14051413.

[49] A.A. C.C. Pais, A. Sousa, M.E. Eusebio, J.S . Redinha, J Phys. Chem. Chem. Phys., 2001, 3, 4001-4009.

[50] J.A. Platts, M.H. Abraham, A. Hersey, D. Butina, J Chem Inf Comput Sci., 1999, 39, 835-845.

[51] A. Kumer, N. Sarker, S. Paul, A. Zannat, Adv. J. Chem. A., 2019, 2, 190202.

How to cite this manuscript: Meysam Shir Mohammadi, Zakiyeh Bayat, Esmat Mohammadinasab. Evaluation of the 1-octanol/water partition coefficient of quinolines and quinolones compounds via free energy estimated in quantum chemical calculations. Eurasian Chemical Communications, 2020, 2(3), 374-386. 